\title{
PERANCANGAN KENDALI WIRELESS ROBOT BERODA DENGAN REMOTE CONTROL MP3 PLAYER BERBASIS MIKROKONTROLER AT89S52
}

\author{
Oleh \\ I Gede Nurhayata \\ Jurusan Teknik Elektronika, FTK, UNDIKSHA
}

\begin{abstract}
ABSTRAK
Kendali wireless dengan remote kontrol infra merah umumnya diterapkan dalam pengendalian peralatan listrik seperti televisi dan music MP3 player. Tujuan dari penelitian ini adalah memanfaatkan fungsi remote kontrol infra merah pada MP3 player dalam aplikasi lain pada sistem kendali robot beroda. Untuk mencapai tujuan penelitian tersebut dilakukan tahapan yaitu perancangan hardware dan software pada mikrokontroller AT89S52 berdasarkan NEC Protocol Infra Red sehingga dapat diketahui kode dari setiap tombol pada remote kontrol MP3 Player. Kemudian kode tersebut digunakan sebagai kendali pada perilaku robot beroda. Hasil penelitian menunjukkan bahwa kode remote kontrol MP3 player khususnya pada tombol (2),(4),(6) dan (8) telah berhasil dideteksi dan mampu mengendalikan perilaku robot beroda antara lain : maju, mundur, belok kiri dan belok kanan.
\end{abstract}

Kata-kata Kunci : robot beroda, remote kontrol, mp3 player, mikrokontroller AT89S52

\begin{abstract}
Wireless control with infrared remote control many applied at control of electric equipment as television and music MP3 player. The goal of this reseach is utilize remote controls infrared function on MP3 player in other application on wheel robot control system. To reach of this research is design hardware and software at mikrokontroller AT89S52 based NEC Protocol Infra Red so gets to be known a code of switchs on remote control MP3 Player. Then that code used to control behaviour of wheel robot. Result of research was successful being detected code of remote control MP3 player in particular at the button (2), (4), (6) and (8) and can controlled behaviour of wheel robot as forward, retreat, veer left and veer right.
\end{abstract}

Keywords : wheel robot, remote control, MP3 player, microcontroller At89S52

\section{PENDAHULUAN}

Dewasa ini sistem kendali di bidang robotika mengalami perkembangan semakin pesat. Hal ini dapat dilihat dari beberapa perguruan tinggi khususnya di Indonesia ikut berperan aktif dalam pengembangan robot melalui berbagai ajang 
kontes robot cerdas indonesia (KRCI). Sistem kendali robot berbasis wireless merupakan salah satu jenis pengendalian robot jarak jauh yang media kendalinya menggunakan gelombang radio (Radio Frequency) maupun gelombang cahaya infra merah. Pengendalian jarak jauh digunakan untuk mengatasi pengendalian robot pada suatu medan atau lingkungan yang sulit dijangkau ataupun yang sangat berbahaya.

Kendali wireless dengan media gelombang radio memiliki jangkauan kendali yang sangat jauh namun informasi sinyal kendalinya sangat mudah mengalami gangguan dari lingkungannya. Sedangkan media kendali dengan gelombang cahaya infra merah seperti halnya pada remote kontrol TV memiliki jangkauan kendali yang terbatas namun informasi kendalinya kebal terhadap perubahan lingkungan. Penelitian ini akan memfokuskan pengendalian wireless pada robot beroda berbasis media infra merah. Sebagai pemancar dan sekaligus kendali robot digunakan remote kontrol yang sudah tersedia dipasaran seperti halnya remote TV maupun MP3 Player. Beberapa penelitian telah banyak dilakukan dalam kendali perangkat listrik dengan remote kontrol TV terutama TV merk Sony (Benny,ddk,2012) dan (Jonansah Liman,2011). Hal tersebut disebabkan karena kesederhanaan dari data protocolnya. Sementara penelitian pengendalian melalui remote kontrol MP3 player masih sangat jarang karena kerumitan data protocolnya yang berbasis NEC dengan 32 bit data. Oleh karena itu, dalam penelitian ini sebagai kendali wireless berbasis infra merah pada robot beroda dipilih menggunakan remote kontrol dari MP3 player.

Remote kontrol MP3 player merupakan suatu alat yang berfungsi untuk mengendalikan pengoperasian MP3 Player dalam jarak jauh. Pada remote kontrol Mp3 player seperti tampak pada Gambar 1 tersedia berbagai macam tombol dengan fungsinya secara khusus seperti pengaturan volume, pemilih file, dan lain sebagainya. Kemampuan yang dimiliki pada remote kontrol tersebut tentunya dapat pula digunakan dalam aplikasi kendali yang lain seperti pada kendali di bidang robot khususnya robot beroda. Perilaku-perilaku robot beroda seperti bergerak maju atau mundur, belok kanan dan belok kiri diharapkan dapat juga dikendalikan melalui remote kontrol MP3 player tersebut. 


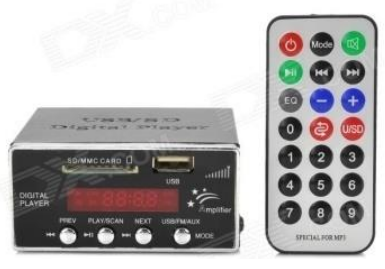

Gambar 1. MP3 player dengan remote kontrol

Permasalahannya adalah bagaimana mengetahui kode dari setiap tombol yang dipancarkan oleh remote kontrol MP3 player sehingga dapat digunakan untuk pengendalian perilaku-perilaku pada robot beroda. Guna mengatasi permasalahan tersebut diperlukan pengetahuan tentang NEC protocol yang ada pada remote kontrol MP3 player dan algoritma pemrograman perangkat lunak pada mikrokontroller AT89S52 sehingga mampu menterjemahkan dan mengendalikan perilaku robot sesuai dengan kode tombol yang diterima. Berdasarkan permasalahan tersebut tujuan penelitian ini adalah merancang perangkat hardware dan software berbasis mikrokontroller AT89S52 sehingga mampu membaca kode dari remote kontrol MP3 Player untuk mengendalikan perilaku pada robot beroda.

Sebuah remote kontrol MP3 player menggunakan cahaya infra merah sebagai media dalam mengirimkan data ke penerima berupa pulsa-pulsa cahaya dengan modulasi frekuensi $40 \mathrm{kHz}$ (Benny, 2012). Sinyal yang dikirimkan merupakan data-data biner. Untuk membentuk data-data biner tersebut, ada tiga metode yang digunakan menurut (Dr. Charles Kim, 2013) yaitu perubahan lebar pulsa, perubahan lebar jeda dan gabungan keduanya. Perubahan lebar pulsa (pulse code signal) seperti tampak pada Gambar 2 dalam mengirimkan kode, lebar jeda tetap yaitu $t$ sedangkan lebar pulsa adalah $2 t$. Jika lebar pulsa dan lebar jeda adalah sama yaitu $t$, berarti yang dikirim adalah bit logika 0 , jika lebar pulsa adalah $2 t$ dan lebar jeda adalah $t$, berarti yang dikirim adalah bit logika 1 . 


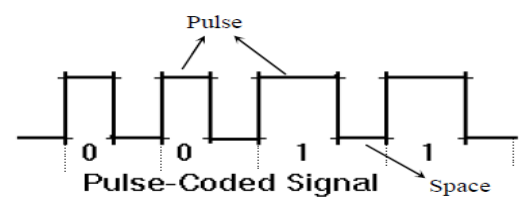

Gambar 2. Pulse code signal

Sedangkan perubahan lebar jeda (space code signals) seperti tampak pada Gambar 3 dalam mengirinkan kode remote kontrol dilakukan dengan cara mengubah lebar jeda, sedangkan lebar pulsa tetap. Jika lebar jeda dan lebar pulsa adalah sama yaitu $t$, berarti yang dikirim adalah bit logika 0 . Jika lebar jeda adalah $3 t$, berarti data yang dikirim adalah bit logika 1 .

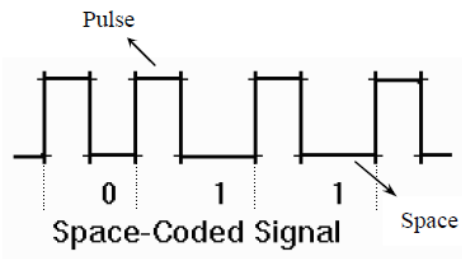

\section{Gambar 3. Space Code Signal}

Sementara perubahan dengan kedua gabungan diatas dinamakan shift code signal seperti tampak pada Gambar 4 dimana dalam mengirimkan kode remote kontrol dengan cara mengubah lebar pulsa dan lebar jeda. Jika lebar jeda adalah $t$, dan lebar pulsa adalah $2 t$, maka ini diartikan sebagai data bit logika 1 . Sebaliknya jika lebar jeda adalah $2 t$ dan lebar pulsa adalah $t$, maka ini diartikan sebagai data bit logika 0 .

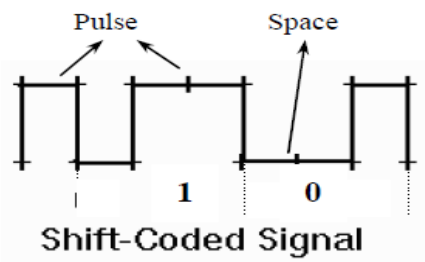

Gambar 4. Shift Code Signals 
Sebelum kode dikirim, terlebih dahulu mengirimkan sinyal awal yang disebut sebagai header. Header adalah sinyal yang dikirimkan sebelum kode sebenarnya dan juga merupakan sinyal untuk mengaktifkan penerima. Header seperti tampak pada Gambar 5 selalu dikirimkan dengan lebar pulsa yang jauh lebih panjang daripada kode. Setelah header dikirimkan, baru kemudian kode remote kontrol. Kode remote kontrol dibagi menjadi dua (2) fungsi yaitu fungsi pertama digunakan sebagai penunjuk alamat peralatan yang akan diaktifkan, fungsi kedua sebagai command atau perintah untuk melaksanakan instruksi dari remote kontrol. Beberapa protocol remote kontrol yang digunakan oleh produsen dalam proses pengiriman data dengan cahaya infra merah diantaranya protocol Sony, NEC dan RC5. Namun pada penelitian ini menggunakan NEC protocol inframerah.

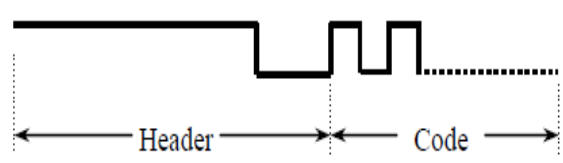

Gambar 5. Pengiriman sinyal header

NEC Protocol infra merah memakai sinyal dengan mode pulsa untuk menyandikan bit-bit pesan. Setiap ledakan pulsa yang ditandai dengan pancaran infra merah memiliki periode waktu 562,5 mikro detik pada frekuensi pembawa $38 \mathrm{kHz}$. Logika bit yang dipancarkan sebagai logika 0 memiliki lebar pulsa dan spasi yang sama 562,5 mikrodetik, sedangkan logika 1 memiliki lebar pulsa sama namun spasinya 2 kali terhadap pulsa sebesar 1,68 mili detik (Altium, 2013).

Ketika sebuah tombol ditekan pada remote kontrol maka sebuah pesan dikirimkan terdiri atas : pulsa start dengan lebar pulsa $9 \mathrm{mS}$ dan spasi 4,5 mS. Kemudian diikuti 16 bit data alamat berikut inversnya, dan terakhir 16 data perintah berikut inversnya dan sebuah pulsa 562,5 uS sebagai tanda akhir pengiriman data. Pada Gambar 6 menunjukkan salah satu contoh pesan yang dikirim dari remote kontrol dengan protocol NEC. 


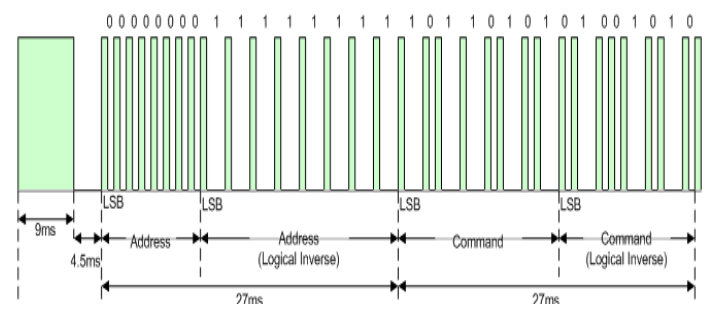

Gambar 6. Contoh IR protocol NEC

Mikrokontroler adalah sebuah sistem mikroprosesor lengkap yang terkandung didalam sebuah chip yang mempunyai masukan dan keluaran serta kendali dengan program yang bisa ditulis dan dihapus dengan cara yang khusus. Mikrokontroler jenis AT89S52 seperti tampak pada Gambar 7 digunakan untuk media penerima data pada blok receiver dan merupakan komponen untuk memproses data masukan yang berasal dari remot kontrol MP3 player yang kemudian mengendalikan output terhadap perilaku robot beroda.

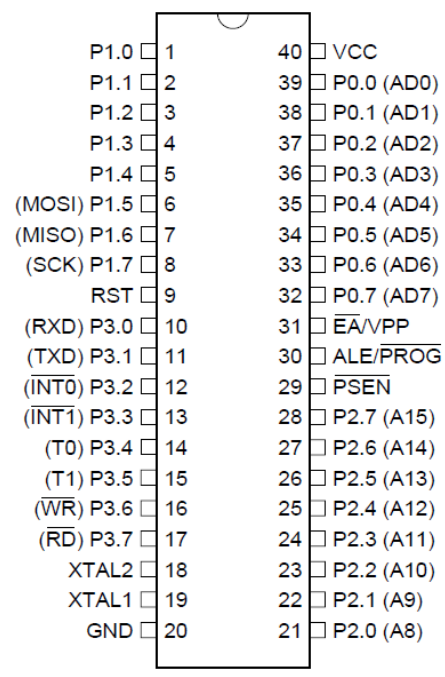

Gambar 7. Mikrokontroller AT89S52

JPTK, UNDIKSHA, Vol. 10, No. 1, Januari 2013 : 15 - 26 
Mikrokontroler AT89S52 merupakan IC yang memiliki $8 \mathrm{~Kb}$ flash PEROM (Programmatable dan Erasable Read Only Memory) yaitu ROM yang dapat ditulis dan dihapus menggunakan perangkat programmer, memiliki 128 x 8 bit internal RAM 32. Programmable I/O lines dan keperluan port parallel. Satu port parallel terdiri dari 8 kaki dengan demikian 32 kaki tersebut membentuk 4 buah port parallel, yang masing-masing dikenal sebagai port-0, port-1, port-2, dan port-3. Nomor dari masing-masing jalur/kaki dari port parallel mulai dari 0 sampai 7 , jalur/kaki pertama port-0 disebut sebagai P0.0 dan jalur / kaki terakhir untuk port-3 adalah P3.7. (Rachmad Setiawan, 2006)

\section{METODE PENELITIAN}

Rancangan penelitian ini meliputi perancangan hardware dan software. Pada Gambar 8 memperlihatkan diagram blok hardware yang terdiri dari penerima inframerah, mikrokontroller AT89S52 dan penggerak roda robot.

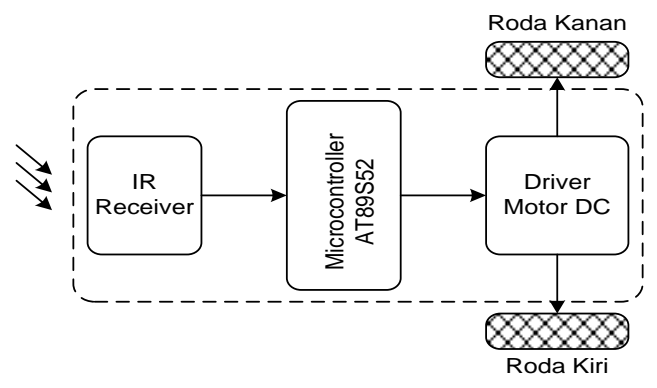

Gambar 8. Digram blok hardware

Prinsip kerja dari Gambar 8 adalah penerima inframerah (IR receiver) berfungsi menangkap isyarat cahaya inframerah yang dipancarkan oleh remote kontrol MP3 player. Kemudian isyarat tersebut diterjemahkan oleh mikrokontroller AT89S52 sehingga diperoleh kode data untuk tombol yang ditekan pada remote kontrol MP3 player. Selanjutnya kode data tombol tersebut oleh mikrokontroller digunakan untuk memilih perilaku robot dan diteruskan ke penggerak motor DC untuk mengaktifkan dua roda robot sesuai dengan perilaku robot yang telah terpilih. 
Jantung utama dari kendali robot beroda ada pada mikrokontroller AT89S52 yang mana tergantung pada perancangan perangkat lunak meliputi penterjemahan kode data dari remote kontrol dan pembentukan perilaku robot. Dalam perancangan kode data remote kontrol diperlukan sumber data berupa pola sinyal pancaran dari remote kontrol . Untuk mengetahui dan mencatat pola yang dipancarkan melalui remote kontrol MP3 player dilakukan dengan alat ukur osiloskop. Pada pola data yang diperoleh akan dilakukan analisis data terhadap nilai periode waktu untuk bit data biner yang mewakili logika 0 dan logika 1, jumlah bit yang diperlukan untuk kode data. Dari analisa pola tersebut akan dibandingkan kecocokan informasinya dengan NEC protocol Infra Red. Setelah data yang diterima telah sesuai dengan protocolnya, maka pada mikrokontroller AT89S52 dirancang suatu algoritma untuk membaca dan membedakan periode bit yang dipancarkan oleh remote kontrol dan menyusun semua bit menjadi suatu kode yang lengkap. Selanjutnya dilakukan pencacatan kode setiap tombol berdasarkan nilai heksadesimal dari pola yang dipancarkan untuk digunakan sebagai referensi dalam mengendalikan perilaku robot. Pada Gambar 9 memperlihatkan algoritma rancangan decoder remote kontrol MP3 Player.

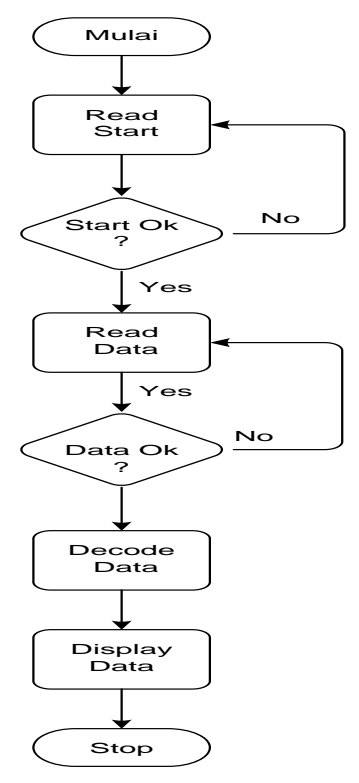

Gambar 9. Algoritma decoder remote kontrol MP3 Player

JPTK, UNDIKSHA, Vol. 10, No. 1, Januari 2013 : 15 - 26 
Berdasarkan algoritma pada Gambar 2 tersebut dapat dijelaskan prinsip kerjanya sebagai berikut : mikrokontroller akan menerima sinyal pancaran infra merah dari remote kontrol Mp3 player. Sinyal pertama yang diterima berupa sinyal "start". Jikalau sinyal start tidak sesuai dengan protokol NEC maka mikrokontroller akan kembali menunggu sinyal pancaran inframerah sampai ada sinyal start yang benar dari remote kontrol. Hal ini sangat penting untuk memastikan bahwa agar tidak sembarang remote kontrol inframerah dapat mengaktifkan robot. Selanjutnya jika sinyal start sudah benar, maka mikrokontroller akan mencacat semua data bit yang diterima berupa bilangan biner (kombinasi logika 0 dan 1). Sesuai protocol NEC jumlah data bit keseluruhan ada 32 bit yakni 16 bit data dan 16 bit alamat. Selama proses penerimaan data bit belum mencapai sebanyak 32 bit maka data dianggap belum lengkap dan mikrokontroller melanjutkan proses penerimaan data. Setelah semua data diterima dilanjutkan dengan penerjemahkan atau penyandian data ke dalam bentuk heksa desimal. Akhirnya data kode heksadesimal tersebut ditampilkan pada layar monitor (PC).

\section{HASIL DAN PEMBAHASAN}

Hasil penelitian ini berupa pola sinyal pancaran dari remote kontrol MP3 player dan pembacaan kode remote kontrol. Pada Gambar 10 memperlihatkan salah satu pola sinyal dari penekanan tombol remote kontrol yang ditampilkan dengan peralatan osiloskop.

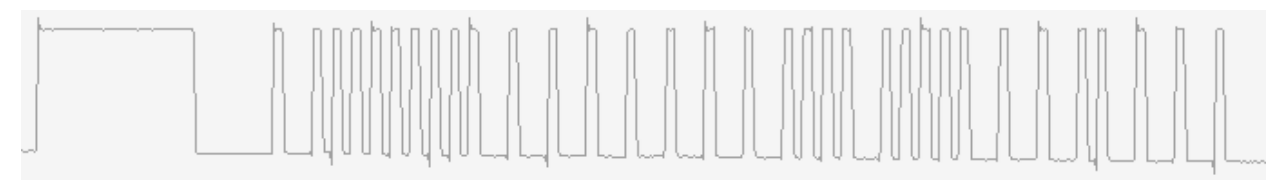

Gambar 10. Pola sinyal kode remote kontrol MP3 player

Pada gambar 10 tersebut terlihat bahwa sinyal start memiliki periode selama 13,5 milidetik. Kemudian untuk logika 0 memiliki periode 1125 mikrodetik dan logika 1 memiliki periode 2250 mikrodetik. Berdasarkan NEC protocol maka pola sinyal 
pancaran remote kontrol tersebut telah sesuai dan valid. Selanjutnya jumlah data yang mengikuti sinyal start terdiri dari 16 bit data dan 16 bit alamat. Jadi secara keseluruhan jumlah datanya 32 bit berarti telah sesuai dengan NEC protocol. Kemudian pencatatan terhadap kode setiap tombol dari remote kontrol yang ditekan dapat dilihat secara keseluruhan pada Tabel 1 dalam bentuk bilangan heksadesimal.

Tabel 1. Data kode tombol remote kontrol MP3 player.

\begin{tabular}{|c|c|}
\hline Tombol & ID Number \\
\hline 0 & \#00FF0DF2 \\
\hline 1 & \#00FF0CF3 \\
\hline 2 & \#00FF18E7 \\
\hline 3 & \#00FF5EA1 \\
\hline 4 & \#00FF08F7 \\
\hline 5 & \#00FF1CE3 \\
\hline 6 & \#00FF5AA5 \\
\hline 7 & \#00FF42BD \\
\hline 8 & \#00FF52AD \\
\hline 9 & \#00FF4AB5 \\
\hline Power & \#00FF45BA \\
\hline Repeat & \#00FF46B9 \\
\hline Mode & \#00FF47B0 \\
\hline $\mathrm{CH}-$ & \#00FF44BB \\
\hline $\mathrm{CH}+$ & \#00FF40BF \\
\hline$E Q$ & \#00FF43BC \\
\hline$<<$ & \#00FF07F8 \\
\hline$>>$ & \#00FF15EA \\
\hline$>\|$ & \#00FF09F6 \\
\hline
\end{tabular}

Pada tabel 1 tersebut nomor ID kode dari setiap penekanan tombol pada remote kontrol MP3 player memiliki ukuran data selebar 32 bit. Dari ukuran data tersebut didekodekan dalam bentuk heksadesimal sehingga memiliki ukuran data selebar 4 byte. Dari 4 byte data tersebut terlihat bahwa 2 byte data memiliki nilai yang sama yaitu \#00FFh. Nilai data ini adalah nilai identitas dari kode peralatan yang dalam hal ini adalah remote kontrol MP3 player. Kemudian 2 byte data berikutnya adalah data alamat dari fungsi setiap tombol yang mana semua datanya jelas berbeda satu sama 
lain. Perbedaan 2 byte data terakhir dari kode tersebut selanjutnya digunakan sebagai indikator dalam mengetahui tombol remote kontrol Mp3 player yang telah ditekan. Jadi 2 byte data terakhir inilah yang akan disimpan pada mikrokontroller sebagai kode pengenal dan sekaligus kunci untuk mengaktifkan salah satu perilaku dari robot beroda.

Pada rancangan penelitian ini, dari tabel 1 dipilih 4 buah tombol yang digunakan untuk mengendalikan perilaku robot yakni tombol 2 untuk gerak robot maju, tombol 4 untuk gerak robot belok kiri, tombol 6 untuk gerak robot belok kanan dan tombol 8 untuk gerak robot mundur. Perilaku-perilaku gerakan robot beroda dengan dua roda dilakukan dengan memberikan kendali pada setiap motor penggeraknya. Misalnya untuk gerakan maju, maka kedua roda robot harus diaktifkan dengan arah putaran ke depan yang sama. Adapun perilaku gerakan robot secara lengkap dapat dilihat pada Tabel 2.

Tabel 2. Tabel kebenaran perilaku robot

\begin{tabular}{|c|c|c|c|c|}
\hline Key & $\begin{array}{c}\text { ID } \\
\text { Number }\end{array}$ & $\begin{array}{c}\text { Gerak } \\
\text { Robot }\end{array}$ & $\begin{array}{c}\text { Motor } \\
\text { Kiri }\end{array}$ & $\begin{array}{c}\text { Motor } \\
\text { Kanan }\end{array}$ \\
\hline 2 & \#00FF18E7 & Maju & CW & CW \\
\hline 4 & $\# 00 F F 087$ & Belok Kiri & OFF & CW \\
\hline 6 & $\# 00 F F 5 A 5$ & $\begin{array}{c}\text { Belok } \\
\text { Kanan }\end{array}$ & CW & OFF \\
\hline 8 & \#00FF52AD & Mundur & CCW & CCW \\
\hline
\end{tabular}

keterangan:

$\mathrm{CW}=$ counterwise

$\mathrm{CCW}=$ counter clockwise

Berdasarkan pada tabel 2 menunjukkan bahwa penelitian ini telah berhasil mengidentifikasi kode tombol remote kontrol MP3 player dan mengaplikasikan kode tersebut sebagai kendali terhadap perilaku robot beroda berbasis mikrokontroller AT89S52. 


\section{SIMPULAN}

Berdasarkan hasil dan pembahasan dalam penelitian ini dapat disimpulkan bahwa remote kontrol MP3 player dapat pula digunakan sebagai kendali aplikasi lain diantaranya kendali pada robot beroda dengan tahapan proses identifikasi kode tombol remote kontrol yang selanjutnya digunakan sebagai pemilih kendali terhadap perilaku-perilaku pada robot beroda. Pengembangan terhadap kendali wireless robot dengan remote kontrol MP3 player dapat dilakukan pada aplikasi robot yang lain terutama yang memiliki jumlah perilaku-perilaku lebih banyak. Hal ini disebabkan karena masih banyak fungsi tombol lain yang tersedia untuk dimanfaatkan sebagai penggerak perilaku robot. Contohnya pada kendali gerak robot lengan dimana terdapat banyak sendi yang harus dikemudikan ataupun pada robot tipe laba-laba (hexapod). Bagi para peneliti lain hal tersebut masih dapat terus dikembangkan.

\section{DAFTAR PUSTAKA}

Altium, 2013, NEC Infrared Transmission Protocol, http://wiki.altium.com/ display/ADOH/NEC+Infrared+Transmission+Protocol, (diakses September 2013)

Benny,dkk, 2012, Pemanfaatan Infrared Remote Universal Sebagai Pengendali Pintu, ORBITH, Vol. 8. No. 3 November 2012 hal : 196-200.

Charles Kim, 2013, Infra Red (IR) Remote Control, http://tinkerish.com/ docs/ir\%20remote\%20control\%20detail.pdf (diakses 15 Oktober 2013)

Johansah Liman, 2011,Pengendali Alat Rumah Tangga Dengan Remote TV Berbasis Mikrokontroller, Vol. 10, No. 21. September-Desember 2011.http://azamamrullah.blogs.ukrida.ac.id/ JKUNUKR/jou/ FTEl/2012/ jkunukr-ns-jou-2012-3011-2398-remote_control-resource.pdf.

Rachmad Setiawan, 2006, Mikrokontroller MCS-51, Penerbit Graha Ilmu, Yogyakarta. 